\begin{tabular}{ccc}
\hline & \\
& International Research Journal of Obstetrics and Gynecology \\
(ISSN:2639-6009)
\end{tabular}

\title{
STUDY OF PLACENTAS OF HYPERTENSIVE MOTHERS ASSISTED IN TWO PUBLIC MATERNITIES OF RECIFE-PE
}

\section{Karinne Gomes Mendonça ${ }^{1 *}$, Evandro Valentim da Silva ${ }^{2}$, Fálba Bernadete Ramos dos Anjos $^{3}$}

${ }^{1}$ UFPE, ${ }^{2}$ Pathology Laboratory of Hospital das ClínicasHC/UFPE, ${ }^{3}$ Professor / Researcher at the Department of Histology and Embryology - UFPE

\section{ABSTRACT}

Objective: Perform the histomorphometric study of the following regions: areas of perivillous fibrin deposition; thickness of the endothelial layer of the vessels; analysis of Tenney-Parker changes. Analyze the Placental Index (IP). Results: It was seen that the weight of the placentas increased according to the weight of the newborn, however, when the variable PI was analyzed as being decisive for the development of a risk-free pregnancy, it was found that this parameter was not significant between the groups studied. $(p<0.05)$. It was found that there is a significant difference in relation to the areas of fibrin deposition $(P<0.05)$ between the groups and that it possibly converges with the data found in the literature in which it could be established that in the $\mathrm{GrH}$ there is a different relationship in this pattern. The findings of the thickness of the middle layer were significant in the $\mathrm{GrH}$ when compared to the $\operatorname{GrN}(p<0.05)$, when this parameter is compared between the Hypertensive Disorders of Pregnancy (HDP) groups, microscopically the PE cases showed prominent changes. I $\mathrm{n}$ the present study, Tenney-Parker changes were prominent and discreet in $75 \%$ of the $\mathrm{GrH}$ placentas versus $20 \%$ in the GrN. However, there are contradictions in the literature regarding the consideration of this finding seen only in Hematoxylin-Eosin staining. Conclusion: Given the above, the presence of syncytial knots, the difference between vessel thickness and areas of fibrin deposition are possibly involved in the pathogenesis of Hypertensive Syndromes, regardless of age and established classifications. In order to evaluate syncytial knots, further studies are needed in this population.

Keywords: placenta; hypertension; endothelium; fibrosis; syncytial knots
*Correspondence to Author:

Karinne Gomes Mendonça

UFPE

How to cite this article:

Karinne Gomes Mendonça, Evandro Valentim da Silva, Fálba Bernadete Ramos dos Anjos.STUDY OF PLACENTAS OF HYPERTENSIVE MOTHERS ASSISTED IN TWO PUBLIC MATERNITIES OF RECIFE-PE. International Research Journal of Obstetrics and Gynecology, 2021, 4:39.

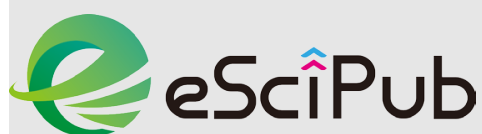

eSciPub LLC, Houston, TX USA. Website: https://escipub.com/ 


\section{INTRODUCTION}

In pregnancy, there are several physiological and psychological adaptations, and according to each pregnant woman there may be development of pathologies, such as, for example, Hypertensive Disorders of Pregnancy (HDP) (BRASIL, 2012). According to Ferrão et al. (2006) its incidence reaches a level of 6 to $8 \%$ of women in this period, which requires special attention from the medical point of view, since the prenatal consultation, in order to avoid major limiting complications for the mother and serious consequences to the fetus (apud ZANATELLI et. al, 2018, p 73).

The MINISTRY OF HEALTH - Department of Informatics of the Brazilian Unified Health System (SUS) (DATASUS) (2016) reports that the number of deaths related to pregnancypuerperal hypertensive disorders was higher in the range of 30 to 39 years. Among the important risk factors for the appearance of HDP, is the temporal factor of the pregnant woman who becomes pregnant at 35 years of age; in addition, the first pregnancy or even a teenage pregnancy. The socioeconomic variables, the nutritional aspect, the ethnicity (black race), family history and previous pregnancy are also considerable complications of hypertension and diabetes mellitus (GONÇALVES et al. 2005; ANGONESI et al., 2007; BRASIL, 2013; apud SILVA, 2015).

HDP are classified into four categories: gestational hypertension, pre-eclampsia and eclampsia, chronic arterial hypertension, chronic hypertension with overlapping pre-eclampsia (American College of Obstetricians and Gynecologists-ACOG, 2013).

According to the High Risk Pregnancy Manual (BRASIL, 2012), HDP corresponds to a blood pressure (BP) level equal to or greater than $140 / 90 \mathrm{mmHg}$, possibly accompanied by proteinuria, that is, excretion of $0.3 \mathrm{~g}$ of proteins or more obtained exclusively by a 24-hour urine test after the 20th week of gestation. In this context, they are considered for the correct measurement of blood pressure (BP) with the pregnant woman seated, with alignment of the arm at the level of the heart using an appropriately sized cuff.

The etiology of hypertensive disease during pregnancy is still not clearly elucidated (BORTOLOTTO, 2008; apud ALMEIDA et al., 2016). However, it has been described that endothelial activation in a generalized way can lead to vasospasm in the maternal organism, which compromises the selective exchange of substances and the coagulation cascade. Such changes are attributed to a maternal immune response that causes the release of antiangiogenic factors by the trophoblast (SASS, 2007; MINAYO, 2010; apud ALMEIDA, 2016, p 397).

According to the National High Blood Pressure Education Program (NHBPEP) (2000) it is important to understand the differentiation of hypertension that precedes pregnancy, which is different from the moment after the 20th week. The reason is that, the first condition is related to a pathophysiological manifestation of the disease, while the second, in contrast, is related to a response in the attempt to adapt to the gestational period that can lead to more serious complications.

The objective of this work is to carry out a macroscopic and microscopic study and to evaluate term placentas of mothers allocated to the hypertensive group $(\mathrm{GrH})$ assisted in two public maternity hospitals, establishing comparative analyzes with a normotensive group (GrN). Perform the histomorphometric study of the following regions: areas of perinous fibrin deposition; thickness of the endothelial layer of the vessels; analysis of Tenney-Parker changes; in addition to obtaining the analysis of the Placental Index (IP) and similarly making a comparative chart of these parameters between the two groups.

\section{MATERIAL AND METHODS}

For this purpose, the research was approved by the Ethics Committee of the Health Sciences 
Center of the Federal University of Pernambuco (CAAE: 81449717.5.0000.5208). This is a crosssectional study conducted with pregnant women assisted in the maternity wards of Hospital das Clínicas - UFPE and Hospital Agamenon Magalhães located in the city of Recife Pernambuco for July 2018 to May 2019.

Placenta samples from mothers who had a normal delivery or cesarean section with only a history of hypertensive disease reported at the time of the interview and investigation were included. In order to eliminate possible bias in the normotensive group (GrN) and hypertensive group $(\mathrm{GrH})$, samples from mothers who had infectious diseases (diabetes, syphilis, HIV) were excluded. For the second, mothers who had clinical signs or symptoms suspected of disorders that pathophysiologically affect the supply of fetal oxygen such as diabetes concomitantly with hypertension were also excluded (GAUSTER, 2012). Regarding the histological evaluation of the placentas, the best preparations in terms of integrity for the study were selected. Thus, 8 placentas belong to $\mathrm{GrH}$ and 5 to $\mathrm{GrN}$.

The placentas were weighed on a Filizola $\AA$ scale (platinum) with precision of one gram. From these data, the PI study was carried out, obtained by the ratio between the weight of the newborn at the moment of birth and the placental weight (RPN / PP) determined in grams (g). Then, $1 \mathrm{~cm}$ fragments of the placentas were made, which were placed in cassettes and fixed in $10 \%$ formaldehyde for later histological analysis.

The placentas were sent to the Laboratory of Toxicity and Cellular Communication, at the Department of Histology and Embryology of the Federal University, where they were kept in their original containers, for processing and continuing the stages of dehydration and diafinization.

After dehydration and diafinization, the processed fragments were embedded in paraffin. Soon after, cuts $(5 \mu \mathrm{m})$ of the tissue were made in a LEITZ $®$ microtome. The preparations were stained using the Hematoxylin-Eosin (HE) technique to assess the histomorphological aspects of the tissues obtained (XAVIER et al., 2011).

The group of placentas analyzed macro and microscopically was defined, so that, the $\mathrm{GrH}$ was established and its 4 subgroups were stratified: Group PE - Placentas of patients with pre-eclampsia (2 interviewees); Grupo HG Placentas of mothers who developed high blood pressure during pregnancy (3 interviewees); Grupo HC - Placentas of mothers diagnosed with chronic hypertension (3 interviewees).

The preparations were analyzed by digitalized image, photographed at $100 x$ and $400 x$ magnification by light microscope with digital camera. To obtain the measurements, the Image $\circledast$ Software was used.

The evaluation of the areas of fibrinoid necrosis located in the perivillous space, as an indication of the area of previous infarction, to establish a comparative analysis (OLIVEIRA, 2004). It was also considered, the evaluation of atherosis was considered due to the deposition of tissue in the middle and intimate layers of the vessel, inducing local inflammation, which determines the recruitment of macrophages to the affected area (OLIVEIRA, 2004). Ultimately, TenneyParker changes or Syncytial knots, that is, clusters of syncytiotrophoblast nuclei or syncytialknots, were identified as prominent, discrete or absent (ARTICO et al., 2009) that may arise in response to the pathophysiological mechanisms of hypertensive syndromes resulting from placental aging early (GÓMEZ, 2018).

The GraphPad Prism 8 program (GraphPad Software Inc., San Diego, CA, USA) was used to assess the size of the thickness of the endothelial layer of the vessels, the areas of perivillous fibrin deposition. A "T" test was performed for comparative purposes (vessel thickness, areas of fibrin) between the two groups. The assessment of syncytial knots was assessed using the Chi-square test with Yates 
correction. The results were considered minimum weight being $1.74 \mathrm{~kg}$ and the significant for $\mathrm{p}<0.05$.

\section{RESULTS AND DISCUSSION}

Regarding the analysis of macroscopic characteristics, it was verified that the weight of the newborns in the $\mathrm{GrH}$ was $3.22 \mathrm{~kg} \pm 76.1$; the

maximum weight $4.27 \mathrm{~kg}$. Regarding the presence of low weight $(<2,500 \mathrm{~g})$, the same group presented $12.5 \%$ of newborns. The GrN average was $3.35 \pm 68$, the minimum weight and the average weight were $2.76 \mathrm{~kg}$ and $4.37 \mathrm{~kg}$, respectively (Figure $2 \mathrm{~A}$ )
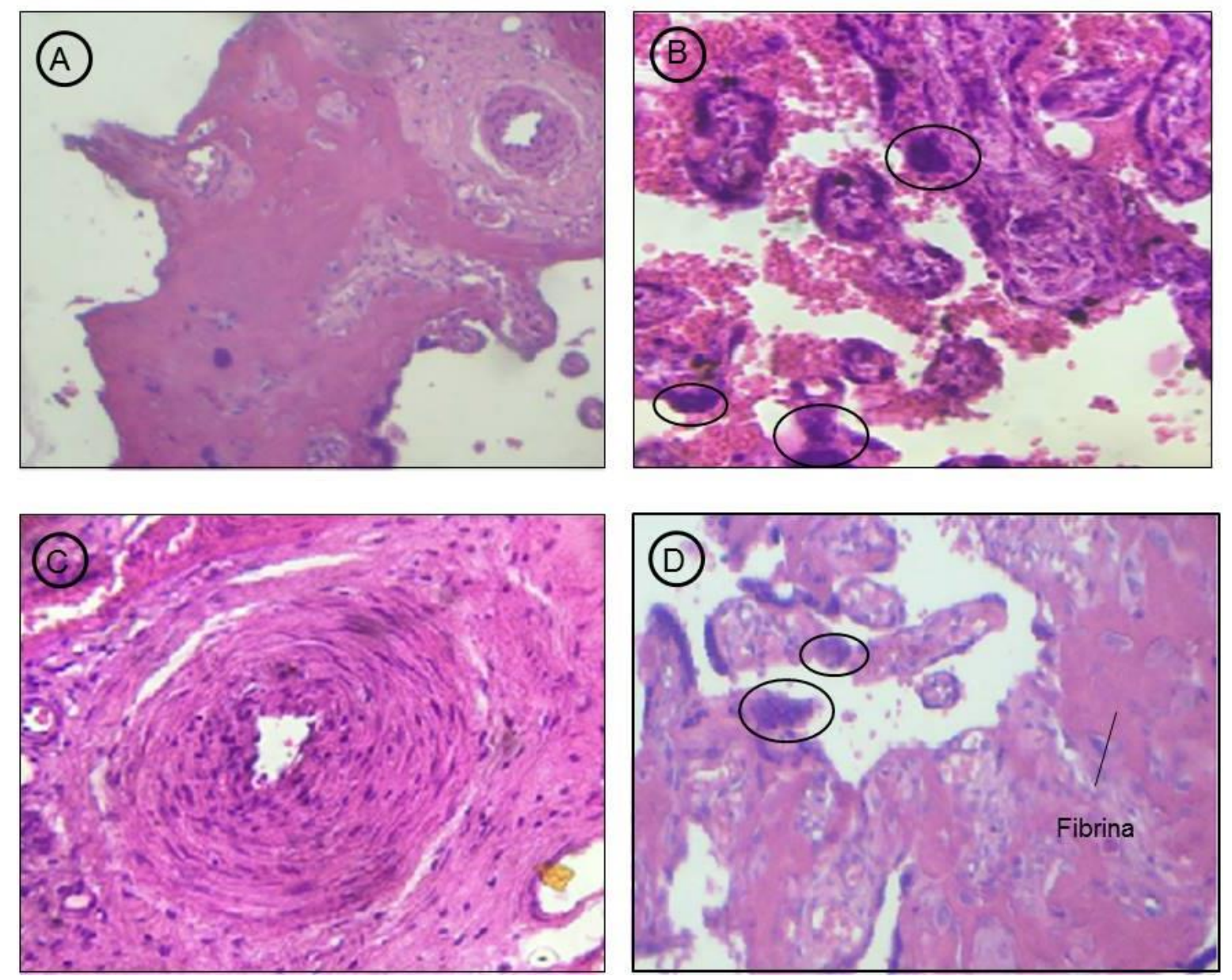

Figure 1 - (A) Photomicrograph of the perivilositary fibrin deposition area (HE, 400X); ( $B$ and $D)$ Photomicrography of regions with Tenney-Parker changes (circumscribed) (HE, 400X); (C) Photomicrograph showing thickening of the villous vessel wall (HE, 1000X).

It was seen that the weight of the placentas increased according to the weight of the newborn, however, when the variable Placental Index (PI) (Figure $2 \mathrm{~B}$ ) was analyzed as being decisive for the development of a risk free pregnancy, it was found that this parameter was not significant among the groups studied ( $p$ $<0.05)$, although Dias et al. (2001) comment in their article that in experimental condition with the Wistar strain there was an increase in $\mathrm{PI}$.
Therefore, it can be considered that, statistically, there was no impairment of fetal or placental weight when comparing the groups. However, it should be considered that in both groups there was a prematurity rate, with the $\mathrm{GrH} 6,66 \%$ (for $93.34 \%$ at term) and the GrN $1.69 \%$ (for $98.33 \%$ at term).

Studies have considered areas of Placental Infarction to be alarming for the development of changes in uteroplacental circulation when corresponding to a region $>3 \mathrm{~cm}$, centrally 
located and with multiple distribution. The risk of hypoxia and progression to growth retardation and fetal death is worrying when the region reaches $10 \%$. A placental morpho-stereological study of mothers with HDP showed that $56.26 \%$ had placental infarction (HERNÁNDEZ, 2018; PATHOLOGICAL ANATOMY, 2019).
A
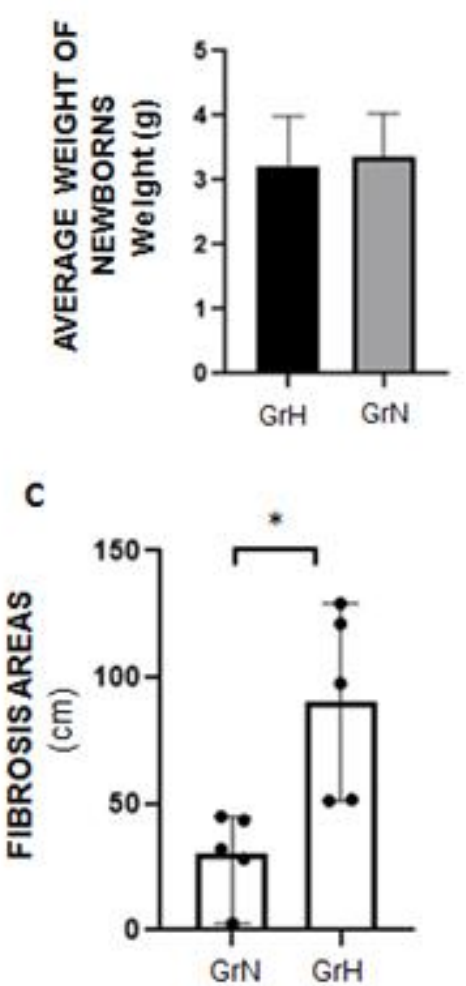

B

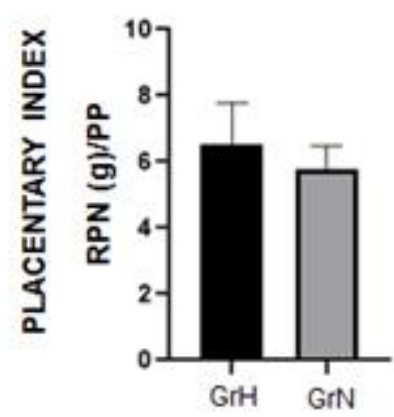

D

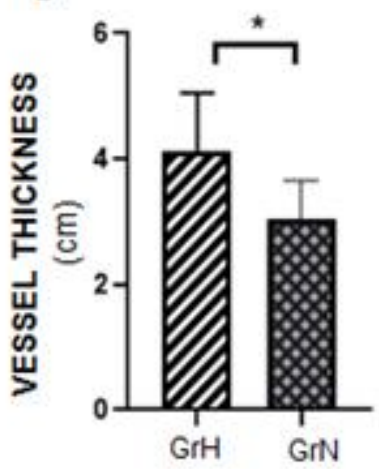

Fig. 2. (A) Average weight of newborns from Grupo Hipertenso and Grupo Normotenso in the population of pregnant women studied in public maternity hospitals in Recife-PE, between July-2018 and May-2019. (B) Determination of the Placental Index in a comparative study of the Hypertensive and Normotensive groups. (C) Analysis of areas of perivilious fibrosis and their relationship between groups in the pregnant population. (D) Analysis of the thickness of the endothelial layer according to the rule of 10 in the studied pregnant population.

Although they are not specific lesions of these syndromes, they are commonly found in hypertensive patients and in cases of pregnancy toxemia (PATHOLOGICAL ANATOMY, 2019).

Commonly, the areas of placental infarction and intervillar fibrin are designated as areas of premature aging, thus named for revealing a histological pattern originating from the disruption of syncytiotrophoblast cells. Among the $\mathrm{SH}$ mentioned, a study found that this finding is present in cases of severe $\mathrm{PE}$, compared to the mild presentation of the disease (LOWDERMILK et al., 2002; MASNEI, 2014).
In another research conducted by Souza (2011), in which the areas of perivilositary fibrin were evaluated, it was identified that in the group of placentas of pregnant women with preeclampsia there was a significant difference when compared to the normal group with a significance level of $(p<0,0001)$, the area being 1.8 times larger in the first.

In the present study, the representative areas of fibrin deposition pattern were evaluated and this comparison is shown in Figure $2 \mathrm{C}$. It was found that there is a significant difference $(P<0.05)$ between the groups and that possibly converges 
with the data found in literature and possibly it can be established that in $\mathrm{GrH}$ there is a different relationship between these areas.

In this study, the findings related to the thickness of the middle layer were considered significant in the $\mathrm{GrH}$ when compared to the $\operatorname{GrN}(\mathrm{p}<0.05)$ as seen in Figure $2 \mathrm{D}$. When the groups of the HDP were analyzed, microscopically, the PE cases showed prominent changes.

Similar to the studies carried out by Ducray (2011) when comparing the thickness of the vessel walls between the normotensive group and the PE patient, a significant difference was found $(P<0.001)$. Despite of not ruling out carrying out studies to conclude his hypotheses, the author still mentions the possible repercussion of this failure in the mother's blood intermediation to the fetus.

In $\mathrm{AH}$, the modification of the intima and media tunics was due to necrosis, caused mainly by fibrinoid deposition and smooth muscle tissue with fat deposition. In addition, along with the deposition of lipid material, there was a concentration of macrophages characterized by strands of irregular appearance under microscopy (MESQUITA, 2003; WEBPATH, 2019).

Considered findings of hypertension, preeclampsia and decidual vasculopathy, the clusters of syncytial knots are representative of the Tenney-Parker changes. This finding may be involved in the evolution of hypertension, but it can also reflect their wear (MADI et al.; 2009; ZIADIE, 2019).

In this study, Tenney-Parker changes were prominent and discreet in $75 \%$ of the $\mathrm{GrH}$ placentas versus $20 \%$ in the $\mathrm{GrN}$, but when treated statistically, it was not considered significant. In this case, it can be considered that, probably, the presence of immature placenta may interfere in the evaluation of this parameter.

In addition, there are contradictions in the literature regarding the consideration of this finding seen only in HE staining, which indicates one more variable for this analysis.

Forgarty (2013) mentions that there may be a distinction between three possible presentations of the syncytial knots. The first, known as real knots, is related to the Tenney-Parker changes as mentioned earlier, in these the chromatin is in the form of a ring in its condensed state. The author also investigated the distinction between the two remaining types, one of them being the result of a tangential cut reflecting the artefactual finding and a third one related to the trophoblastic proliferative visualized in his experiments when he used the specific markers for this phase in the Immunohistochemistry Technique.

Therefore, it was possible to establish that the present study aimed to assess the presence or absence of these changes. Thus, the need for more in-depth studies cannot possibly be ruled out to possibly establish a relationship between the different types of syncytial knots.

\section{CONCLUSION}

Given the above, the difference between vessel thickness and areas of fibrin deposition is possibly involved in the pathogenesis of Hypertensive Syndromes, regardless of age and established classifications, however, in order to evaluate syncytial knots, further studies are needed in this population. In addition, it was observed that this relationship could not be established, when the Placental Index was verified, in this population. The evaluation of these data in the histological analysis of placentas allows us to infer their importance, because, in this way, it contributes to the study of the pathology in question.

\section{REFERENCES}

1. ALMEIDA, G. B. S.; SOUZA, M. C. M. The knowledge of pregnant women about hypertension in pregnancy. Rev. APS, Juiz de Fora-MG, v. 19, n. 3, p. 396-402, 2016.

2. AMERICAN COLLEGE OF OBSTETRICIANS AND GYNECOLOGISTS. Task Force on Hypertension in Pregnancy. Hypertension in pregnancy. Report of the American College of 
Obstetricians and Gynecologists' Task Force on Hypertension in Pregnancy. Obstetrics \& Gynecology, Washington-DC, v. 122, n. 5, p. 1122-1131, 2013.

3. PATHOLOGICAL ANATOMY, UFMG. Villitis and placental infarctions. Available at: <http://anatpat.unicamp.br/lamgin28.html>. Accessed: 05 Jun. 2019.

4. ARTICO, L. G. et al. Histopathological changes in human placentas related to hypertensive syndromes. Brazilian Journal of Gynecology and Obstetrics, Caxias do Sul-RGS, v. 31, n.1, p. 1016, 2009.

5. BRAZIL. Ministry of Health. Health Care Secretariat. Department of Strategic Programmatic Actions. High-risk pregnancy: technical manual. 5. ed. - Brasília: Publisher of the Ministry of Health, 2012. 302 p.

6. MINISTRY OF HEALTH [Internet]. Executive Secretary. Datasus. Mortality indicator for pregnancy-puerperal hypertensive disorders. Available at: <http://tabnet.datasus.gov.br/cgi/tabcgi.exe?sim/ cnv/obt10uf.def>. Accessed on: 19 Apr. 2019.

7. DIAS, R .; RUDGE, M. V. C ; TRINDADE, J. C. S. Experimental Arterial Hypertension and Pregnancy in Rats: Effects on Placenta Weight and Placental Index. Brazilian Journal of Gynecology and Obstetrics, Botucatu - SP, v. 23, n. 2, p. 87-91, 2001.

8. DUCRAY, J.F.; THAJASVARIE N.; MOODLEY, J. Pilot study of comparative placental morphometry in pre-eclamptic and normotensive pregnancies suggests possible maladaptations of the fetal component of the placenta. European Journal of Obstetrics \& Gynecology and Reproductive Biology, v. 156, n. 1, p. 29-34, 2011.

9. FOGARTY N. M.; FERGUSON-SMITH, A.C.; BURTON, G. J. Syncytial knots (TenneyParker changes) in the human placenta: evidence of loss of transcriptional activity and oxidative damage. The American Journal of Pathology, Cambridge-UK, v. 183, n. 1, p. 144-152, 2013.

10. GÓMEZ, R. P; OTTONE, N. E; BIANCH, H. Morphological Features of the Human Placenta and its Free Chorionic Villi in Normal Pregnancies and those with Diabetes and High Blood Pressure. Literature Review. International Journal of Morphology, Temuco-Chile, v. 36, n. 4, p. 11831192, 2018.

11. HERNÁNDEZ, M. O. Stereological morpho studio in placentas of hypertensive pregnant women with simple embarazo. Multimed. Medical Journal. Granma. Granma, Cuba, 2018; 22 (3).

IRJOG: https://escipub.com/international-research-journal-of-obstetrics-and-gynecology/
12. LOWDERMILK, D. L.; PERRY, S. E.; BOBAK, I. M. Maternal Nursing Care. 5th ed. Porto Alegre: Artmed Editora, 2002, p. 297-313.

13. MASNEI, L. T. A. Nursing care provided to patients with pre-eclampsia and eclampsia in an emergency care service: intervention proposal. Journal of the USP School of Nursing, v. 50, n. 2, p. 324-334, 2014.

14. OLIVEIRA, L. F. Study of placental changes in pregnant women with antiphospholipid syndrome: anatomical-clinical correlations. Thesis (Doctorate in Sciences). University of Sao Paulo. São Paulo, 2004.

15. National High Blood Pressure Education Program Working Group on High Blood Pressure in Pregnancy. American Journal of Obstetrics and Gynecology, v. 183, n. 1, 2000.

16. SILVA, R. V. G. Specific hypertensive disease of pregnancy - intervention project to work with pregnant women in the territory of the family health strategy in the municipality of Pedra do Anta, Minas Gerais. Completion of course work. Federal University of Minas Gerais. Faculty of Medicine. Collective Health Education Center. Conselheiro Lafaiete, 31f. 2015.

17. SILVA, S. D. et al. When to introduce pharmacological treatment in Pre-Eclampsia. Brazilian journal of health and biomedical sciences, Rio de Janeiro-RJ, v. 14, n. 2, p. 87, 93, 2015.

18. SOUZA, D. A. et al. Increase in perivilositary fibrinoid material in placental pregnancies with pre-eclampsia. Brazilian Journal of Pathology and Laboratory Medicine, Rio de Janeiro, Vol. 47 n. 1, 2011.

19. ZANATELLI, C. Hypertensive syndromes in pregnancy: strategies to reduce maternal mortality. Revista Integrada Saúde, v. 9, n. 17, p. 73-81, 2016. Available at: $<$ http://local.cnecsan.edu.br/revista/index.php/sa ude/index>. Accessed on April 12, 2019.

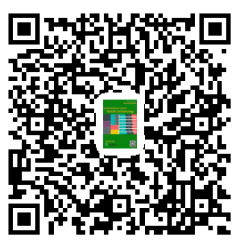

